\title{
Mapping the knowledge and understanding of menarche, menstrual hygiene and menstrual health among adolescent girls in low- and middle-income countries
}

Venkatraman Chandra-Mouli ${ }^{1 *+}$ and Sheila Vipul Patel ${ }^{2+}$

\begin{abstract}
Background: Menstruation is a natural physiological process that requires proper management. Unlike other normal bodily processes, menstruation is linked with religious and cultural meanings that can affect the perceptions of young girls as well as the ways in which the adults in the communities around them respond to their needs.
\end{abstract}

Objectives: This review aims to answer the following questions: (1) how knowledgeable are adolescent girls in low- and middle-income countries about menstruation and how prepared are they for reaching menarche, (2) who are their sources of information regarding menstruation, (3) how well do the adults around them respond to their information needs, (4) what negative health and social effects do adolescents experience as a result of menstruation, and (5) how do adolescents respond when they experience these negative effects and what practices do they develop as a result?

Methods: Using a structured search strategy, articles that investigate young girls' preparedness for menarche, knowledge of menstruation and practices surrounding menstrual hygiene in LMIC were identified. A total of 81 studies published in peer-reviewed journals between the years 2000 and 2015 that describe the experiences of adolescent girls from 25 different countries were included.

Results: Adolescent girls in LMIC are often uninformed and unprepared for menarche. Information is primarily obtained from mothers and other female family members who are not necessarily well equipped to fill gaps in girls' knowledge. Exclusion and shame lead to misconceptions and unhygienic practices during menstruation. Rather than seek medical consultation, girls tend to miss school, self-medicate and refrain from social interaction. Also problematic is that relatives and teachers are often not prepared to respond to the needs of girls.

Conclusion: LMIC must recognize that lack of preparation, knowledge and poor practices surrounding menstruation are key impediments not only to girls' education, but also to self-confidence and personal development. In addition to investment in private latrines with clean water for girls in both schools and communities, countries must consider how to improve the provision of knowledge and understanding and how to better respond to the needs of adolescent girls.

Keywords: Menarche, Menstruation, Menstrual health, Menstrual health problems, Menstrual hygiene management, Adolescent girls

\footnotetext{
* Correspondence: chandramouliv@who.int

${ }^{\dagger}$ Equal contributors

1 Department of Reproductive Health and Research, World Health

Organization, Avenue Appia 20, 1211 Geneva 27, Switzerland

Full list of author information is available at the end of the article
} 


\section{Plain English summary}

Our paper maps the knowledge, attitudes, beliefs and practices surrounding menarche, menstrual hygiene and menstrual health among adolescent girls in low and middle income countries in order to inform the future design of relevant policies and programming.

Our study of over 80 journal articles from a number of low and middle income countries confirmed that:

- Many adolescent girls start their periods uninformed and unprepared

- Mothers are the primary source of information, but they inform girls too-little and too-late and often communicate their own misconceptions

- Because menstruation is widely seen as polluting and shameful, girls are often excluded and shamed in their homes and in their communities

- Many do not have the means for self-care and do not get the support they need when they face problems, which hinders their ability to carry on with everyday activities and may also establish a foundation for life-long disempowerment

Efforts to respond to girls' needs are fragmented and piece-meal. There is growing acknowledgement that efforts are more likely to be successful if they come together in a whole-of-community approach that involves schools, health facilities, and homes and communities to:

- Educate girls about menstruation

- Create norms that see menstruation as healthy and positive, not shameful and dirty

- Improve access to sanitary products, running water, functional toilets and privacy for self-care

- Improve care for and support by girls' families when they have their periods

- Improve access to competent and caring health workers when they experience menstrual health problems

\section{Background}

Girls in many low- and middle-income countries (LMIC) enter puberty with knowledge gaps and misconceptions about menstruation, unprepared to cope with it and unsure of when and where to seek help. This is because the adults around them, including parents and teachers, are themselves ill-informed and uncomfortable discussing sexuality, reproduction and menstruation (which frequently comes laden with dirty, polluting and shameful connotations).

To respond to the increased international attention on empowering girls through the United Nation's Sustainable Development Goals, this review aims to map the knowledge, attitudes, beliefs and practices surrounding menarche, menstrual hygiene and menstrual health among adolescent girls in LMIC in order to inform the future design of relevant policies and programming. To do this, our objectives are to answer the following questions: (1) how knowledgeable are girls in LMIC about menstruation and how prepared are they for reaching menarche, (2) who are their sources of information regarding menstruation, (3) how well do the adults around them respond to their information needs, (4) what negative health and social effects do adolescents experience as a result of menstruation, and (5) how do adolescents respond when they experience these negative effects and what practices do they develop as a result?

\section{Methods}

Our literature search aimed to identify articles that evaluated the knowledge of girls regarding menstruation, their information sources, the health and social effects of menstruation, and how adolescents and adults responded to these effects. We searched Google Scholar, PubMed and EBSCO's Global Health database for articles in peer-reviewed journals published between 2000 and 2015. To identify relevant literature, we used the following search strategy: (menarche or menstruation or menstrual health or menstrual hygiene or menstrual management) and (adolescence or adolescent or youth or young) and (female or girl or women) and (knowledge or belief or practice or experience).

Through a title and abstract review, papers in English that addressed the experiences of adolescent girls (ages 10-19) in LMIC were retained. Full text articles were reviewed to determine whether studies addressed one or more of our five questions. Given the limited research available, descriptive overviews and interventions using quantitative, qualitative, or mixed methods of any sample size were all included. ${ }^{1}$ While the focus of this paper is on menstrual experiences, studies that reported on the preparedness and attitudes of pre-menarcheal girls were included so long as data were stratified by those who had and had not reached menarche. To complement our search, we reviewed the reference lists of the included articles and identified a small number of additional studies that met these broad criteria. Finally, we searched and included publications by United Nations agencies and international non-governmental organizations that responded to how organizations and their LMIC partners are responding to the needs of girls.

\section{Results}

A total of 81 articles were identified after discarding duplicate articles and those that did not meet inclusion criteria (Table 1). 
Table 1 Study characteristics

\begin{tabular}{|c|c|}
\hline Characteristic & Frequency \\
\hline \multicolumn{2}{|l|}{ Design } \\
\hline Descriptive & 70 \\
\hline Intervention & 11 \\
\hline \multicolumn{2}{|l|}{ Method } \\
\hline Mixed methods & 16 \\
\hline Qualitative & 7 \\
\hline Quantitative & 58 \\
\hline \multicolumn{2}{|l|}{ Region } \\
\hline East Africa (Ethiopia, Kenya, Malawi, Tanzania, Uganda) & 10 \\
\hline North Africa (Egypt) & 4 \\
\hline West Africa (Ghana, Nigeria) & 10 \\
\hline North/Central America (Mexico) & 3 \\
\hline South America (Brazil) & 1 \\
\hline East Asia (China) & 1 \\
\hline Southeast Asia (Malaysia) & 6 \\
\hline South Asia (Bangladesh, India, Nepal, Pakistan, Sri Lanka) & 39 \\
\hline West Asia (Iran, Jordan, Lebanon, Turkey) & 7 \\
\hline \multicolumn{2}{|l|}{ Setting $^{\mathrm{a}}$} \\
\hline Mix & 21 \\
\hline Rural & 23 \\
\hline Urban & 30 \\
\hline \multicolumn{2}{|l|}{ School status ${ }^{a}$} \\
\hline Mix of school-going and out-of-school & 12 \\
\hline School-going & 63 \\
\hline
\end{tabular}

${ }^{a}$ All included studies did not specify setting or girls' school status

How knowledgeable are girls about menstruation and how prepared are they for reaching menarche?

Girls across LMIC have limited knowledge and understanding about menstruation prior to reaching menarche. The proportion of girls that were aware ranged from $2.8 \%$ of rural girls questioned in Rajasthan, India [1] to all urban girls in Turkey [2] (Table 2). Village-based meetings for girls in a Maharashtra, India were tested as a platform for disseminating health messages, and significantly contributed to an increase from $35.1 \%$ of girls interviewed in 2003 to $55.4 \%$ of girls interviewed in 2007 being aware of menstruation before its onset ( $p$-value $<0.05$ ) [3].

Three quarters of 1,573 Chinese girls surveyed rated their menstrual knowledge as inadequate or very inadequate [4]. Even so, girls with any knowledge often hold misconceptions about menstruation. For example, a study conducted in rural Nepal reported that $6.0 \%$ of 150 girls surveyed recognized menstruation as a physiological process while $82.0 \%$ believed it was a curse [5]. Understanding that menstruation is a natural bodily function was higher at $19.3 \%$ in Pakistan [6], 18.3-86.3\% in five
Indian states [1, 7-13], and $96.7 \%$ in Nigeria [14]. Menstruation was considered a curse, disease, or representation of $\sin$ by some girls in five Indian states [7-12, 15] and Uganda [16]. Prior to receiving health education at school, $72.4 \%$ girls in India considered menstrual blood impure [17].

An additional knowledge gap among girls is a lack of awareness regarding the origins of menstrual blood-no more than a third of girls correctly identified the uterus as the source of menstrual blood in four Indian states $[7,12,15,18,19]$ and rural Nepal [5]. One study in a fourth Indian state reported almost no girls being aware of the source of their blood (2.5\%) [8], while another nearly two-thirds being aware (63.3\%) [13]. In cities in Pakistan [6] and Nigeria [14], 37.2 and 78.7\% identified the uterus as the source, respectively, compared to $82.9 \%$ of school-going girls in rural Uganda [16]. Only a third of rural-living, high school girls surveyed in India associated the attainment of menarche with the capacity to conceive [10].

Age had a significant influence on slum dwellers' knowledge in India, with older girls more knowledgeable about menstruation than their younger counterparts ( $p$-value $<0.05)$ [7]. Similar findings were reported among Nigerian schoolgirls ( $p$-value $<0.05$ ) [20]. Compared to those not attending school, awareness was greater among schoolgirls in India [1] and Pakistan [6]. Education level had a significant influence on menstrual knowledge in India [7] and Nigeria [14] ( $p$-value <0.05).

\section{Who are girls' sources of information?}

Across LMIC studied, mothers were often the most frequently cited source of information and advice for girls regarding menstruation (Table 3 ). Compared to girls residing in urban parts of Ethiopia [21] and India [22], those in rural settings reported their mothers as an information source less often (possibly because there were other female relatives they could turn to). Following mothers, sisters were the next most common resource in four Indian states [1, 11, 12, 23], Mexico [24], Nepal [25], Nigeria [20, 26], Pakistan [6], and Turkey [27], though they were utilized by less than a quarter of girls. In some contexts, sisters and friends surpassed mothers as the primary source of information $[6,13,28,29]$.

A majority of studies which examined the roles of teachers and/or health professionals as providers of menstrual information ranked them as the least common sources compared to female relatives and friends (Egypt [30], Ghana [31], India [1, 7, 11, 12, 15, 32-35], Jordan [36], Malaysia [37-39], Nepal [25], Nigeria [14, 20, 26, 40-42], Sri Lanka [43], and Turkey [27].) Teachers were cited as a source by less than $5.0 \%$ of girls questioned in three Indian states [1, 32, 33], 
Table 2 Awareness of menstruation prior to menarche

\begin{tabular}{|c|c|c|c|c|c|}
\hline First author, Year & Country & Setting & School status & $\mathrm{N}$ & Aware \\
\hline \multicolumn{6}{|l|}{ North Africa } \\
\hline Eswi 2012 [45] & Egypt & Urban & School-going & 200 & $74.0 \%$ \\
\hline \multicolumn{6}{|l|}{ South Asia } \\
\hline Bosch 2008 [28] & Bangladesh & Rural & Unclear & 156 & $35.0 \%$ \\
\hline Khanna 2005 [1] & India & Mix & Out-of-school & 358 & $5.6 \%$ \\
\hline Dambhare 2012 [32] & India & Mix & School-going & 561 & $75.6 \%$ \\
\hline Juyal 2013 [65] & India & Mix & School-going & 453 & $64.5 \%$ \\
\hline Khanna 2005 [1] & India & Mix & School-going & 372 & $9.8 \%$ \\
\hline Thakre 2011 [12] & India & Mix & School-going & 387 & $37.0 \%$ \\
\hline Khanna 2005 [1] & India & Rural & Mix & $N R^{\mathrm{a}}$ & $2.8 \%$ \\
\hline Dasgupta 2008 [8] & India & Rural & School-going & 160 & $67.5 \%$ \\
\hline Shanbhag 2012 [10] & India & Rural & School-going & 329 & $57.9 \%$ \\
\hline Sudeshna 2012 [15] & India & Rural & School-going & 190 & $47.4 \%$ \\
\hline Dhingra 2009 [29] & India & Rural & Unclear & 200 & $64.0 \%$ \\
\hline Tiwari 2006 [11] & India & Unclear & School-going & 763 & $62.7 \%$ \\
\hline Khanna 2005 [1] & India & Urban & Mix & $N R^{\mathrm{a}}$ & $12.1 \%$ \\
\hline Omidvar 2010 [46] & India & Urban & School-going & 336 & $64.5 \%$ \\
\hline Yasmin 2013 [13] & India & Urban & School-going & 147 & $42.2 \%$ \\
\hline Bobhate 2011 [7] & India & Urban & Unclear & 241 & $20.3 \%$ \\
\hline Udgiri 2010 [23] & India & Urban & Unclear & 342 & $18.4 \%$ \\
\hline Ali 2010 [6] & Pakistan & Urban & Government school & 425 & $47.8 \%$ \\
\hline Ali 2010 [6] & Pakistan & Urban & Out-of-school & 425 & $38.8 \%$ \\
\hline Ali 2010 [6] & Pakistan & Urban & Private school & 425 & $34.1 \%$ \\
\hline \multicolumn{6}{|l|}{ West Asia } \\
\hline Reis 2011 [27] & Turkey & Urban & Mix & 310 & $67.4 \%$ \\
\hline Ersoy 2004 [2] & Turkey & Urban & School-going & 1017 & $100.0 \%$ \\
\hline
\end{tabular}

$N R$ Not reported

${ }^{\mathrm{a}}$ Of 730 girls, the number in rural versus urban settings was not specified

Nepal [25], and Sri Lanka [43]. At most, a third of subjects in urban Nigeria cited teachers as a source [41]. While students in urban Malaysia were more likely than those in rural settings to cite teachers as a source, a considerable number had never encountered menstrual-related topics in school [39]. Less than $1.0 \%$ of girls in a rural part of India [33] and urban parts of Jordan [36] reported having received information regarding menstruation from health professionals. At most, a quarter of study participants in urban Nigeria cited health professionals as a source [41].

Some studies reported mass media, such as radio, television, newspapers, magazines, books, and the Internet either as the only resource available to girls or as supplements to other sources of information (Egypt [30, 44, 45], Ghana [31], India [15, 29, 32, 34, 35, 46], Jordan [36], Malaysia [37-39, 47, 48], Nepal [25], Nigeria [40-42], Sri Lanka [43], and Turkey $[2,27])$. In a few instances, such sources were reported by more than a quarter of girls: $72.4 \%$ in Nigeria [41], 92.2\% in Egypt [30], and 29.2-43.6\% in Malaysia [37, 38, 47, 48].

Girls reported not having received information from any source in some studies. As few as 6.8 and $7.0 \%$ of girls in urban Nigeria [42] and Egypt [45], respectively, and $7.8 \%$ of a mix of urban- and rural-living girls in Ethiopia [21] reported having no source. A study of urban- and rural-living girls in India reported a quarter without a source [32]. In rural Nepal, $76.0 \%$ of girls reported having no menstrual information source [5].

How well do adults respond to girls' information needs? Whether by a relative, friend, or other community member, the information on menstrual health and hygiene provided to adolescents is not always timely nor is it adequate.

Researchers found that mothers and other relatives in India [1, 7] and Tanzania [49] who did provide girls with information often did not do so until after 
Table 3 Most commonly reported sources of menstrual information

\begin{tabular}{|c|c|c|c|c|c|}
\hline First author, Year & Country & Setting & School status & $\mathrm{N}$ & $\begin{array}{l}\text { Most common } \\
\text { source (\%) }\end{array}$ \\
\hline \multicolumn{6}{|l|}{ East Africa } \\
\hline Zegeye 2009 [21] & Ethiopia & Mix & School-going & 564 & Mother (39.7\%) \\
\hline \multicolumn{6}{|l|}{ North Africa } \\
\hline Abd El-Hameed 2011 [44] & Egypt & Mix & School-going & 160 & Mother (59.4\%) \\
\hline El-Gilany 2005 [30] & Egypt & Mix & School-going & 642 & $\begin{array}{l}\text { Mother }(92.2 \%) \text {, mass } \\
\text { media }(92.2 \%)\end{array}$ \\
\hline Eswi 2012 [45] & Egypt & Urban & School-going & 200 & Mother (53.0\%) \\
\hline \multicolumn{6}{|l|}{ West Africa } \\
\hline Gumanga 2012 [31] & Ghana & Urban & School-going & 456 & Parent (80.2\%) \\
\hline Adinma 2009 [26] & Nigeria & Urban & School-going & 550 & Mother (48.4\%) \\
\hline Ajah 2015 [42] & Nigeria & Urban & School-going & 482 & Mother $(81.5 \%$ \\
\hline Aniebue 2009 [40] & Nigeria & Urban & School-going & 495 & Mother (71.5\%) \\
\hline Lawan $2010[20]^{f}$ & Nigeria & Urban & School-going & 385 & Mother (35.3\%) \\
\hline Oche 2012 [14] & Nigeria & Urban & School-going & 122 & $\begin{array}{l}\text { Mother or grandmother } \\
(56.6 \%)\end{array}$ \\
\hline \multicolumn{6}{|l|}{ Central America } \\
\hline Marván 2012 [24] ${ }^{f}$ & Mexico & Urban & School-going & 405 & Mother (78.0\%) \\
\hline \multicolumn{6}{|l|}{ South Asia } \\
\hline Bosch 2008 [28] & Bangladesh & Rural & Unclear & 86 & Sister (29.0\%) \\
\hline Dambhare 2012 [32] ${ }^{a}$ & India & Mix & School-going & 561 & Mother (38.2\%) \\
\hline Thakre $2011[12]^{a}$ & India & Mix & School-going & 143 & Mother (71.3\%) \\
\hline Khanna 2005 [1] & India & Rural & Mix & - & Mother (55.1\%) \\
\hline Dasgupta $2008[8]^{a}$ & India & Rural & School-going & 160 & Mother (37.5\%) \\
\hline Kanotra 2013 [92] & India & Rural & School-going & 323 & Mother (94.4\%) \\
\hline Kotecha 2009 [33] & India & Rural & School-going & 340 & Mother (32.9\%) \\
\hline Mudey 2010 [34] & India & Rural & School-going & 300 & Mother (40.7\%) \\
\hline Shanbhag 2012 [10] & India & Rural & School-going & 506 & Mother (55.1\%) \\
\hline Sudeshna $2012[15]^{a}$ & India & Rural & School-going & 80 & Mother or sister (45.0\%) \\
\hline Dhingra 2009 [29] & India & Rural & Unclear & 200 & Friend (83.0\%) \\
\hline Tiwari 2006 [11] & India & Unclear & School-going & 486 & Mother (60.7\%) \\
\hline Khanna 2005 [1] & India & Urban & Mix & - & Mother (66.8\%) \\
\hline Sharma $2008[64]^{\mathrm{b}}$ & India & Urban & Mix & 156 & Mother (73.7\%) \\
\hline Omidvar $2010[46]^{\mathrm{a}}$ & India & Urban & School-going & 215 & Mother (54.0\%) \\
\hline Yasmin 2013 [13] & India & Urban & School-going & 147 & Friend (20.4\%) \\
\hline Bobhate 2011 [7] $^{c}$ & India & Urban & Unclear & 241 & Mother (75.9\%) \\
\hline Udgiri $2010[23]^{a}$ & India & Urban & Unclear & 63 & Mother (63.5\%) \\
\hline Adhikari 2007 [5] & Nepal & Rural & School-going & 150 & Coursebook (14.7\%) \\
\hline Sharma 2003 [25] & Nepal & Urban & School-going & 96 & Mother (37.5\%) \\
\hline Ali $2010[6]^{a}$ & Pakistan & Urban & Government school & 203 & Sister (35.5\%) \\
\hline Ali $2010[6]^{a}$ & Pakistan & Urban & Out-of-school & 165 & Sister (49.7\%) \\
\hline Ali $2010[6]^{a}$ & Pakistan & Urban & Private school & 145 & Mother (37.9\%) \\
\hline Chandraratne $2011[43]^{\mathrm{b}}$ & Sri Lanka & Urban & School-going & 473 & Mother (67.0\%) \\
\hline
\end{tabular}


Table 3 Most commonly reported sources of menstrual information (Continued)

\begin{tabular}{|c|c|c|c|c|c|}
\hline \multicolumn{6}{|l|}{ Southeast Asia } \\
\hline Lee 2006 [37] & Malaysia & Mix & School-going & 2247 & Mother (80.0\%) \\
\hline Wong $2011[47]^{\mathrm{e}}$ & Malaysia & Rural & School-going & 984 & Mother (62.3\%) \\
\hline Wong $2011[38]^{d}$ & Malaysia & Rural & School-going & 577 & Mother (31.7\%) \\
\hline Wong $2011[48]^{d}$ & Malaysia & Urban & School-going & 407 & Mother (62.7\%) \\
\hline \multicolumn{6}{|l|}{ West Asia } \\
\hline Jarrah 2012 [36] & Jordan & Urban & School-going & 408 & Mother (57.1\%) \\
\hline Reis 2011 [27] & Turkey & Urban & Mix & 310 & Mother (18.7\%) \\
\hline Ersoy 2004 [2] & Turkey & Urban & School-going & 1017 & Mother (55.7\%) \\
\hline
\end{tabular}

${ }^{\text {aPre-menarcheal sources }}$

${ }^{b}$ Sources among those with menstrual problems

cPost-menarcheal sources

${ }^{\mathrm{d}}$ Sources among those who ever received information

esources among those with dysmenorrhea

${ }^{f}$ First source

menarche. In Mexico, however, 94.0\% of girls reported that they had discussed menstruation with their mothers prior to menarche [24]. A study in Nigeria reported $55.2 \%$ of school-going girls were "trained" prior to reaching menarche, which included being made aware of what to expect at menarche and how to collect blood and dispose of materials [40]. Further, parents' education level was found to have a significant influence on pre-menarcheal knowledge in Nigeria ( $p$-value $<0.05)$ as girls whose parents had received tertiary education were the most likely to have been trained [40]. In India $[15,33]$ and Kenya $[50,51]$, girls reported that little information about menstruation was provided and nearly no explanation. Sources of information may have their own misconceptions about menstruation, which they may pass on. Mothers interviewed in Bangladesh attributed menstruation to God [28]. During initiation rites in Malawi, misconceptions, like men can get hurt if they come in contact with menstrual blood, are told to girls by female relatives [52].

Given the link between menstruation and the ability to conceive, mothers interviewed in Bangladesh did not consider it appropriate to discuss the matter with their pre-menarcheal daughters [28]. Both mothers and teachers, most of whom were male, in Kenya cited discomfort as an impediment to discussing menstruation with girls [53]. Teachers in rural Tanzania warned their students that their mothers would be very upset if told about their reaching menarche [49]. This may be a result of cultural taboos that prevent parents from discussing sex-related topics with their daughters. Taboos were also cited as a by the few teachers in Tanzania who wanted to provide support to their students [54]. Teachers in Kenya did not perceive menstrual education as part of their role nor did they feel properly prepared to share information with their students [53].
A majority of teachers (70-90\%) at schools in Ghana who had been trained to use play-based approaches to promote menstrual knowledge and practices were confident in discussing menstruation with their students compared to their counterparts at schools not using similar approaches who had limited conversations [55]. Overall, $82.4 \%$ of study participants in Jordan felt they were not adequately prepared for reaching menarche [36]. Of girls in rural Nepal who received information from a parent, friend or a coursebook, an overwhelming majority felt menstrual-related topics were not properly taught [5]. Four-fifths of school-going girls questioned in Egypt wanted more information [30]. However, girls in Malaysia [39] and Tanzania [54] reported feeling ashamed, embarrassed and uncomfortable when inquiring about menstruation from adults.

\section{What are the emotional, physical and social impacts of menstruation on girls?}

Anticipated and experienced menstruation-related impacts were mostly negative (with some positive impacts when girls were better informed/prepared). While eight out of every ten study participants in Mexico expected at least one positive change to occur upon reaching menarche, all expected at least one negative change to occur; the nine most expected changes among urban and rural girls were negative, e.g., discomfort, worry, cramps [56]. Overall, $89.4 \%$ of anticipated changes reported by pre-menarcheal girls and $88.7 \%$ of experienced changes reported by post-menarcheal girls were negative [57].

\section{Emotional impacts}

A quarter to eight out of every ten girls questioned in various LMIC reported not being mentally prepared for reaching menarche (Brazil [58], China [4], India [11], Jordan [36], Mexico [24, 56], Nepal [25], 
Nigeria [40],). Many girls had negative reactions to their first period (Table 4). For example, a majority of school-going girls in one study in India described menarche as a shocking or fearful event and many cried upon seeing their blood [18].

Some school-going girls perceived menstrual blood to be dirty or described feeling disgusted by their period: $30.5 \%$ in Lebanon [59], $48.9 \%$ versus $72.8 \%$ in rural versus urban Malaysia [38, 48], and $10.0-23.4 \%$ in two Indian states [11, 17, 34]. Additionally, girls in Kenya revealed that "the girl with her period is the one to hang her head" because she becomes the target of unwanted and sometimes unkind attention [53]. Mood swings and irritability connected to menstruation were both reported by more than two-thirds of schoolgirls in India [60], Lebanon [59], and Malaysia [38, 48].

Not all feelings about reaching menarche were negative; more than half of schoolgirls questioned in China [4], India [9], and Malaysia [38, 48] felt pride in maturing. Focus groups in rural and urban settings in Kenya [51] and Tanzania [61] with female students revealed a similar sentiment. The more school-going girls in Mexico knew about menstruation, the less negative their attitudes $(p$-value $<0.05)$; and the more prepared they felt, the more positive their attitudes $(p$ - value $<0.0001)$ [24]. A later menarcheal age and higher socioeconomic status seemed to further reduce negative reactions among girls in Malaysia [39] and Turkey [2], respectively.

\section{Physical impacts}

Physical impacts of menstruation that were commonly reported across studies included premenstrual symptoms or syndrome and painful periods. These outcomes were almost always reported by at least half of the sample (Table 5). At most, 93.2\% of rural-living girls in India reported experiencing a premenstrual symptom [62] and 94.4\% of school-going girls in Egypt reported experiencing dysmenorrhea [44]. In Ethiopia, girls with premenstrual symptoms suffered more often from dysmenorrhea than those without ( $82.4 \%$ versus $40.3 \%$, respectively) [21]. Of girls with dysmenorrhea in Ghana, nearly two-thirds experienced symptoms during most or all cycles [31]. A majority of rural-living girls surveyed in Malaysia considered dysmenorrhea a normal aspect of menstruation [47].

\section{Social impacts}

Activities of daily living or daily routines were restricted by menstruation among a quarter of girls in rural India

Table 4 Negative reaction upon reaching menarche

\begin{tabular}{|c|c|c|c|c|c|}
\hline First author, Year & Country & Setting & School status & N & Negative reaction ${ }^{a}(\%)$ \\
\hline \multicolumn{6}{|l|}{ West Africa } \\
\hline Aniebue 2009 [40] & Nigeria & Urban & School-going & 495 & $50.3 \%$ \\
\hline Oche 2012 [14] & Nigeria & Urban & School-going & 122 & $53.3 \%$ \\
\hline \multicolumn{6}{|l|}{ Central America } \\
\hline Marván 2001 [57] & Mexico & Urban & School-going & 98 & $15.3 \%$ \\
\hline \multicolumn{6}{|l|}{ East Asia } \\
\hline Tang 2003 [4] & China & Unclear & School-going & 1,573 & $72.0 \%$ \\
\hline \multicolumn{6}{|l|}{ South Asia } \\
\hline Bosch 2008 [28] & Bangladesh & Rural & Unclear & 86 & $64.0 \%$ \\
\hline Mudey 2010 [34] & India & Rural & School-going & 300 & $43.7 \%$ \\
\hline Shanbhag 2012 [10] & India & Rural & School-going & 329 & $44.1 \%$ \\
\hline Tiwari 2006 [11] & India & Unclear & School-going & 763 & $20.6 \%$ \\
\hline Bobhate 2011 [7] & India & Urban & Unclear & 241 & $64.7 \%$ \\
\hline Udgiri 2010 [23] & India & Urban & Unclear & 342 & $31.0 \%$ \\
\hline Adhikari 2007 [5] & Nepal & Rural & School-going & 150 & $96.7 \%$ \\
\hline Ali 2010 [6] & Pakistan & Urban & Government school & 425 & $55.8 \%$ \\
\hline Ali 2010 [6] & Pakistan & Urban & Out-of-school & 425 & $62.6 \%$ \\
\hline Ali 2010 [6] & Pakistan & Urban & Private school & 425 & $55.1 \%$ \\
\hline \multicolumn{6}{|l|}{ West Asia } \\
\hline Reis 2011 [27] & Turkey & Urban & Mix & 310 & $43.9 \%$ \\
\hline Ersoy 2004 [2] & Turkey & Urban & School-going & 1,017 & $49.8 \%$ \\
\hline
\end{tabular}

${ }^{\mathrm{a}}$ Reported shock, panic, confusion, tension, fear, shame or embarrassment at menarche 
Table 5 Physical impacts of menstruation

\begin{tabular}{|c|c|c|c|c|c|c|c|c|c|}
\hline First author, Year & Country & Setting & School status & N & $\mathrm{PMS}^{\mathrm{a}}$ & Severe pain ${ }^{b}$ & Headache & Swelling ${ }^{c}$ & Fatigue $^{d}$ \\
\hline \multicolumn{10}{|l|}{ East Africa } \\
\hline Zegeye 2009 [21] & Ethiopia & Mix & School-going & 565 & $75.4 \%$ & $72.0 \%$ & NR & NR & NR \\
\hline \multicolumn{10}{|l|}{ North Africa } \\
\hline Abd El-Hameed 2011 [44] & Egypt & Mix & School-going & 160 & NR & $94.4 \%$ & NR & NR & NR \\
\hline \multicolumn{10}{|l|}{ West Africa } \\
\hline Gumanga 2012 [31] & Ghana & Urban & School-going & 456 & $N R$ & $74.4 \%$ & NR & NR & NR \\
\hline Ajah 2015 [42] & Nigeria & Urban & School-going & 482 & $75.1 \%$ & $64.1 \%$ & NR & NR & NR \\
\hline Aniebue 2009 [40] & Nigeria & Urban & School-going & 495 & & $26.7 \%$ & NR & NR & NR \\
\hline \multicolumn{10}{|l|}{ Central America } \\
\hline Marván 2001 [57] & Mexico & Urban & School-going & 98 & $N R$ & NR & $6.1 \%$ & NR & $14.3 \%$ \\
\hline \multicolumn{10}{|l|}{ South America } \\
\hline Pitangui 2013 [58] & Brazil & Urban & School-going & 174 & NR & $73.0 \%$ & $14.4 \%$ & $61.5 \%$ & $27.6 \%$ \\
\hline \multicolumn{10}{|l|}{ South Asia } \\
\hline Dambhare 2012 [32] & India & Mix & School-going & 561 & $56.3 \%$ & $56.2 \%$ & $26.7 \%$ & NR & NR \\
\hline Thakre 2012 [22] & India & Mix & School-going & 387 & $55.8 \%$ & $61.0 \%$ & NR & NR & NR \\
\hline Baidya 2014 [77] & India & Rural & Mix & 200 & $8.5 \%$ & $59.5 \%$ & $16.0 \%$ & NR & $4.0 \%$ \\
\hline Rana 2015 [63] & India & Rural & Mix & 400 & $N R$ & $46.8 \%$ & NR & NR & NR \\
\hline Bodat 2013 [67] & India & Rural & School-going & 622 & $N R$ & $58.1 \%$ & NR & NR & NR \\
\hline Kanotra 2013 [92] & India & Rural & School-going & 323 & $3.1 \%$ & $18.3 \%$ & NR & NR & NR \\
\hline Mudey 2010 [34] & India & Rural & School-going & 300 & $N R$ & NR & $25.7 \%$ & NR & NR \\
\hline Shanbhag 2012 [10] & India & Rural & School-going & 329 & $N R$ & $61.3 \%$ & NR & NR & NR \\
\hline Wasnik 2015 [72] & India & Rural & School-going & 435 & $17.9 \%$ & $62.3 \%$ & $6.7 \%$ & NR & NR \\
\hline Patil 2013 [62] & India & Rural & Unclear & 440 & $93.2 \%$ & $28.0 \%$ & $1.8 \%$ & NR & NR \\
\hline Chaudhuri $2012[60]^{e}$ & India & Unclear & School-going & 224 & NR & $59.8 \%$ & $28.1 \%$ (of 128) & NR & $70.3 \%$ (of 128) \\
\hline Sharma 2008 [64] & India & Urban & Mix & 198 & $63.1 \%$ & $67.2 \%$ & $16.7 \%$ & $11.1 \%$ & $48.0 \%$ \\
\hline Chandraratne $2011[43]^{f}$ & Sri Lanka & Urban & School-going & 594 & $66.2 \%$ & $61.3 \%$ & $28.1 \%$ (of 393) & NR & $29.1 \%$ (of 393) \\
\hline Nair 2012 [73] & India & Urban & School-going & 3443 & $N R$ & $72.4 \%$ & $13.9 \%$ & NR & $36.1 \%$ \\
\hline Sharma 2003 [25] & Nepal & Urban & School-going & 96 & $N R$ & $69.8 \%$ & NR & NR & NR \\
\hline \multicolumn{10}{|l|}{ Southeast Asia } \\
\hline Lee 2006 [37] & Malaysia & Mix & School-going & 2247 & $74.7 \%$ & $69.3 \%$ & NR & NR & NR \\
\hline Wong 2011 [47] & Malaysia & Rural & School-going & 1295 & $N R$ & $76.0 \%$ & NR & NR & NR \\
\hline Wong 2011 [38] & Malaysia & Rural & School-going & 1295 & $63.1 \%$ & NR & $47.3 \%$ & $12.6 \%$ & $81.1 \%$ \\
\hline Wong 2010 [78] & Malaysia & Urban & School-going & 1075 & NR & $74.5 \%$ & NR & NR & NR \\
\hline Wong 2011 [48] & Malaysia & Urban & School-going & 1076 & $56.5 \%$ & NR & $38.4 \%$ & $13.1 \%$ & $75.4 \%$ \\
\hline \multicolumn{10}{|l|}{ West Asia } \\
\hline Poureslami 2002 [79] & Iran & Urban & School-going & 250 & $N R$ & $71.2 \%$ & NR & NR & NR \\
\hline Jarrah 2012 [36] & Jordan & Urban & School-going & 490 & $N R$ & $N R$ & $50.4 \%$ & NR & $80.6 \%$ \\
\hline Santina 2012 [59] & Lebanon & Urban & School-going & 389 & $N R$ & $74.3 \%$ & $22.8 \%$ & $34.6 \%$ & NR \\
\hline Eryilmaz 2009 [80] $^{9}$ & Turkey & Unclear & School-going & 1951 & $N R$ & $72.2 \%$ & $26.1 \%$ (of 1408) & NR & $11.9 \%$ (of 1408) \\
\hline Reis 2011 [27] & Turkey & Urban & Mix & 310 & NR & $23.9 \%$ & NR & NR & NR \\
\hline
\end{tabular}

PMS Premenstrual symptoms/syndrome, NR Not reported

aPremenstrual symptoms or premenstrual syndrome

bIncluding dysmenorrhea

'Swelling or bloating

${ }^{\mathrm{d}}$ Fatigue or dizziness

e Headaches and fatigue reported among girls with dysmenorrhea who agreed to provide more information

fHeadaches and fatigue reported among girls with PMS

${ }^{9}$ Headaches and fatigue reported among girls with dysmenorrhea 
[63], a third of female students in Brazil [58] and Egypt [44], and among $60.0 \%$ of slum dwellers in India [64]. In urban Sri Lanka, schoolgirls with premenstrual syndrome had significantly more disruptions to their daily routines than those without [43]. Daily activities are further limited by taboos related to what and who menstruating girls are able to come in contact with. Menstruating girls in India and Nepal are sometimes limited from entering kitchens or bedrooms to ensure menstrual blood does not contaminate food or others $[1,5,11,12,63,65]$. Household work such as cooking was often cited as 'not allowed' for menstruating girls in India [1, 12, 63], Kenya [53], and Nepal [5]. Female students from a mix of rural and urban settings in India reported limitations on who they could touch while menstruating $[12,18]$. Other social limitations frequently reported include avoiding physical or social activities (e.g., sports and functions), abstaining from religious activities or missing school (Table 6).

Girls in Malaysia [38, 48] and Pakistan [6] reported restrictions on religious activities due to menstruation. Studies reporting the complete abstinence of religious activities come mostly from India; this practice was reported by $44.7-94.2 \%$ of girls interviewed [7-10, 12, 13, 15, 34, 60, 63, 64]. Education level had a significant influence on the practice of avoiding holy places in India $(p$-value $<0.05)$ [23]. Mothers interviewed in Nigeria revealed that they advised their daughters to refrain from praying during their periods [41]. This aligns with another study in Nigeria, in which $43.4 \%$ of girls reported abstaining from religious activities [14]. Health education interventions in Bangladesh [66] and India [19] did not result in significant declines in religious restrictions among girls during their periods.

When asked if girls can go to school while menstruating, $70.7 \%$ of girls in rural Nepal responded 'no' [5]. Actual absenteeism reported in various LMIC did not reach that level, instead ranging from $2.0 \%$ of urban-living girls in Nigeria [40] to $61.7 \%$ of ruralliving girls in Uganda [16]. Focus groups in Malaysia revealed that dysmenorrhea may have a greater impact on school absenteeism for girls in urban settings than those in rural settings [38]. Dysmenorrhea was significantly associated with missing school among urban-living girls in Lebanon [59] as was pain severity among those in Brazil [58] ( $p$-value $<0.05$ ). Menstrual disorders in general was significantly associated with missing school among ruralliving girls in India ( $p$-value $<0.001)$ [67]. In Kenya, male teachers reportedly teased girls about menstruation when they returned to school after being absent for a few days [53]. Although the teachers denied this, they noted that they were concerned with girls being distracted in class [53]. Teachers interviewed in Ghana shared similar concerns about girls being distracted and missing school [68]. Girls, themselves, in India [60], Malaysia [47, 48], and
Uganda [16] associated menstruation with poor academic performance and low grades.

A puberty education intervention with provision of sanitary pads in a non-randomized trial in Ghana significantly improved girls' school attendance $(p$-value $<0.001)$ [69]. Alternatively, a randomized trial in Nepal [70] demonstrated that providing menstrual cups may improve convenience and mobility, and one in Kenya [71] demonstrated that they can reduce distractions associated with leakage and improve school attendance.

\section{How do girls respond to negative effects and what practices do they develop?}

To address the physical impacts of menstruation described in Table 5, some girls reported using traditional medicine or remedies (Bangladesh [72], Brazil [58], India [63, 64, 73, 74], Malaysia [37, 47, 48, 75], Sri Lanka [43],) and others reported taking medication to relieve pain, often by self-medicating or consulting pharmacies (Bangladesh [72], Brazil [58], Egypt [44], India [60, 63, 64, 74], Iran [76], Malaysia [39, 47, 75], Nigeria [42], and Turkey $[27,77])$. Consultation of health professionals for menstrual-related problems was minimal, generally reported by less than a fifth of girls (Bangladesh [72], Brazil [58], Ethiopia [21], India [60, 63, 64, 73, 74], Iran [76], and Malaysia [37, 47, 48],). However, one study did report that $69.8 \%$ of Indian girls with problems sought attention from a health professional [7]. Another study in India reported that $19.2 \%$ of girls with a problem never discussed it with anyone-a health professional, relative, or friend [64]. Girls in Bangladesh were significantly more likely to consult someone regarding their problems after participating in 12 health education sessions over the course of six months than at baseline $(p$-value $<0.01)[66]$.

General lack of adult guidance related to menstruation may contribute to the variation in basic hygiene management practices such as use of sanitary absorbents and bathing daily across LMIC (Table 7). Use of sanitary pads to absorb blood ranged from $2.0 \%$ of schoolgirls in rural Nepal [5] to $69.1-93.8 \%$ of urbanliving girls in Nigeria [14, 20, 40, 41]. All but one study of girls in rural parts of seven Indian states reported greater proportions of girls using cloth compared to sanitary pads $[1,8,10,12,15,18,29,34,63$, $67,78]$. Sanitary pad use was significantly higher among urban-living girls in India [22] and Ethiopia [21] as was use of sanitary pads or new cloth among school-going girls in India [1] $(p$-value $<0.01)$. A quasi-experimental study testing village-based meetings for girls in India as a platform for disseminating health messages contributed to significant increases in the use of sanitary pads and a decrease in the reuse of cloth ( $p$-value $<0.05$ ) [3]. While fewer girls using sanitary pads in one 
Table 6 Social impacts of menstruation

\begin{tabular}{|c|c|c|c|c|c|c|c|}
\hline First author, Year & Country & Setting & School status & N & $\begin{array}{l}\text { Avoid physical or } \\
\text { social activities }^{a}(\%)\end{array}$ & $\begin{array}{l}\text { Abstain from religious } \\
\text { activities (\%) }\end{array}$ & $\begin{array}{l}\text { Miss school or } \\
\text { work (\%) }\end{array}$ \\
\hline \multicolumn{8}{|l|}{ East Africa } \\
\hline Zegeye 2009 [21] & Ethiopia & Mix & School-going & 407 & NR & NR & $48.2 \%$ \\
\hline Boosey 2014 [16] & Uganda & Rural & School-going & 140 & NR & NR & $61.7 \%$ (of 133) \\
\hline \multicolumn{8}{|l|}{ North Africa } \\
\hline Abd El-Hameed 2011 [44] & Egypt & Mix & School-going & 160 & 54 & NR & NR \\
\hline \multicolumn{8}{|l|}{ West Africa } \\
\hline Adinma 2009 [26] & Nigeria & Urban & School-going & 550 & $N R$ & NR & $4.5 \%$ \\
\hline Ajah 2015 [42] & Nigeria & Urban & School-going & 482 & NR & NR & $12.2 \%$ \\
\hline Aniebue 2009 [40] & Nigeria & Urban & School-going & 495 & $37.6 \%$ & NR & $2.0 \%$ \\
\hline Oche 2012 [14] & Nigeria & Urban & School-going & 122 & $4.9 \%$ & $43.4 \%$ & NR \\
\hline \multicolumn{8}{|l|}{ South America } \\
\hline Pitangui $2013[58]^{\mathrm{b}}$ & Brazil & Urban & School-going & 127 & NR & $N R$ & $30.7 \%$ \\
\hline \multicolumn{8}{|l|}{ South Asia } \\
\hline Dambhare 2012 [32] ${ }^{b}$ & India & Mix & School-going & 561 & NR & NR & $13.9 \%$ \\
\hline Juyal 2013 [65] & India & Mix & School-going & 453 & $8.6 \%$ & $87.4 \%$ & NR \\
\hline Thakre 2011 [12] & India & Mix & School-going & 387 & $N R$ & $44.7 \%$ & $5.2 \%$ \\
\hline Rana 2015 [63] & India & Rural & Mix & 400 & $28.0 \%$ & $53.2 \%$ & $26.4 \%^{c}$ \\
\hline Bodat 2013 [67] & India & Rural & School-going & 622 & $N R$ & $N R$ & $43.2 \%$ \\
\hline Dasgupta 2008 [8] & India & Rural & School-going & 136 & $36.3 \%$ & $60.0 \%$ & $13.8 \%$ \\
\hline Kanotra $2013[92]^{\mathrm{b}}$ & India & Rural & School-going & 59 & $76.6 \%$ & $N R$ & $N R$ \\
\hline Mudey 2010 [34] & India & Rural & School-going & 300 & NR & $87.0 \%$ & NR \\
\hline Shanbhag 2012 [10] & India & Rural & School-going & 329 & NR & $94.2 \%$ & NR \\
\hline Sudeshna 2012 [15] & India & Rural & School-going & 190 & $N R$ & $75.8 \%$ & $37.9 \%$ \\
\hline Chaudhuri $2012[60]^{b}$ & India & Unclear & School-going & 128 & $53.5 \%$ & NR & $25.8 \%$ \\
\hline Sharma 2008 [64] & India & Urban & Mix & 156 & $25.6 \%$ & $N R$ & $17.2 \%(\text { of } 116)^{c}$ \\
\hline Goel 2011 [9] & India & Urban & School-going & 478 & $42.7 \%$ & $76.2 \%$ & $14.0 \%$ \\
\hline Sharma 2003 [25] & Nepal & Urban & School-going & 67 & $20.0 \%$ & NR & NR \\
\hline Yasmin 2013 [13] & India & Urban & School-going & 147 & $18.4 \%$ & $90.5 \%$ & NR \\
\hline Bobhate 2011 [7] & India & Urban & Unclear & 241 & $24.1 \%$ & $90.0 \%$ & NR \\
\hline Ali 2010 [6] & Pakistan & Urban & Government school & 425 & $67.3 \%$ & NR & NR \\
\hline Ali 2010 [6] & Pakistan & Urban & Out-of-school & 425 & $58.1 \%$ & NR & NR \\
\hline Ali 2010 [6] & Pakistan & Urban & Private school & 425 & $58.1 \%$ & $N R$ & $N R$ \\
\hline \multicolumn{8}{|l|}{ Southeast Asia } \\
\hline Lee 2006 [37] & Malaysia & Mix & School-going & 2247 & $N R$ & NR & $7.0 \%$ \\
\hline Wong $2011[47]^{b}$ & Malaysia & Rural & School-going & 984 & $58.6 \%$ & $N R$ & $18.1 \%$ \\
\hline Wong $2010[78]^{b}$ & Malaysia & Urban & School-going & 801 & $50.2 \%$ & $N R$ & NR \\
\hline Wong 2011 [48] & Malaysia & Urban & School-going & 1076 & $61.5 \%$ & NR & NR \\
\hline \multicolumn{8}{|l|}{ West Asia } \\
\hline Poureslami 2002 [79] & Iran & Urban & School-going & 250 & $33.0 \%$ & NR & $15.2 \%$ \\
\hline Santina 2012 [59] & Lebanon & Urban & School-going & 389 & NR & NR & $41.4 \%$ \\
\hline
\end{tabular}

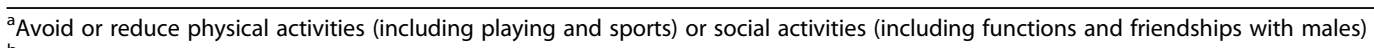

${ }^{\mathrm{b}}$ Among girls with dysmenorrhea

${ }^{\mathrm{C} A m o n g}$ school-going girls 
Table 7 Menstrual hygiene management practices (\%)

\begin{tabular}{|c|c|c|c|c|c|c|c|c|c|}
\hline First author, Year & Country & Setting & School status & $\mathrm{N}$ & $\begin{array}{l}\text { Use sanitary } \\
\text { pads (\%) }\end{array}$ & $\begin{array}{l}\text { Use sanitary pads } \\
\text { and cloth (\%) }\end{array}$ & $\begin{array}{l}\text { Use old or } \\
\text { new cloth (\%) }\end{array}$ & $\begin{array}{l}\text { Use other } \\
\text { material }^{a}(\%)\end{array}$ & $\begin{array}{l}\text { Bathe } \\
\text { daily (\%) }\end{array}$ \\
\hline \multicolumn{10}{|l|}{ East Africa } \\
\hline Zegeye 2009 [21] & Ethiopia & Mix & School-going & 565 & $37.6 \%$ & NR & $62.5 \%$ & NR & NR \\
\hline \multicolumn{10}{|l|}{ North Africa } \\
\hline Abd El-Hameed 2011 [44] & Egypt & Mix & School-going & 160 & NR & NR & NR & NR & $100.0 \%^{\mathrm{b}}$ \\
\hline El-Gilany 2005 [30] & Egypt & Mix & School-going & 642 & $66.8 \%$ & NR & $27.9 \%$ & $5.3 \%$ & $70.9 \%^{b}$ \\
\hline \multicolumn{10}{|l|}{ West Africa } \\
\hline Iliyasu 2012 [41] & Nigeria & Urban & Mix & 184 & $81.0 \%$ & $N R$ & NR & NR & NR \\
\hline Aniebue 2009 [40] & Nigeria & Urban & School-going & 495 & $69.1 \%$ & NR & $9.1 \%$ & $21.8 \%$ & NR \\
\hline Lawan 2010 [20] & Nigeria & Urban & School-going & 371 & $93.8 \%$ & $N R$ & $6.2 \%$ & NR & NR \\
\hline Oche 2012 [14] & Nigeria & Urban & School-going & 122 & $86.9 \%$ & NR & $9.0 \%$ & $4.1 \%$ & NR \\
\hline Boosey $2014[16]^{c}$ & Uganda & Rural & School-going & 140 & $47.1 \%$ & $N R$ & $87.1 \%$ & $37.1 \%$ & $N R$ \\
\hline \multicolumn{10}{|l|}{ South Asia } \\
\hline Khanna 2005 [1] & India & Mix & Out-of-school & 304 & $2.0 \%$ & NR & $90.9 \%$ & $0.3 \%$ & NR \\
\hline Juyal 2013 [65] & India & Mix & School-going & 453 & $38.4 \%$ & $26.7 \%$ & $34.9 \%$ & NR & $63.6 \%$ \\
\hline Khanna 2005 [1] & India & Mix & School-going & 307 & $6.2 \%$ & $N R$ & $68.4 \%$ & $0.7 \%$ & NR \\
\hline Khanna 2005 [1] & India & Rural & Mix & 281 & $3.2 \%$ & $N R$ & $92.2 \%$ & $0.7 \%$ & $N R$ \\
\hline Rana 2015 [63] & India & Rural & Mix & 400 & $39.0 \%$ & NR & $61.0 \%$ & NR & NR \\
\hline Bodat 2013 [67] & India & Rural & School-going & 622 & $48.1 \%$ & $N R$ & $51.9 \%$ & $N R$ & $N R$ \\
\hline Dasgupta 2008 [8] & India & Rural & School-going & 160 & $11.3 \%$ & $40 \%$ & $48.8 \%$ & NR & NR \\
\hline Kanotra 2013 [92] & India & Rural & School-going & 323 & $89.5 \%$ & $N R$ & $10.5 \%$ & NR & $N R$ \\
\hline Mudey 2010 [34] & India & Rural & School-going & 300 & $15.7 \%$ & NR & $46.7 \%$ & NR & NR \\
\hline Narayan 2001 [18] & India & Rural & School-going & 327 & $1.7 \%$ & $48 \%$ & $82.5 \%$ & NR & NR \\
\hline Shanbhag 2012 [10] & India & Rural & School-going & 329 & $44.1 \%$ & $21.2 \%$ & $34.7 \%$ & NR & $88.8 \%$ \\
\hline Sudeshna 2012 [15] & India & Rural & School-going & 190 & $13.2 \%$ & $24.2 \%$ & $62.6 \%$ & NR & NR \\
\hline Thakre 2011 [12] & India & Rural & School-going & 146 & $30.8 \%$ & NR & $69.2 \%$ & NR & NR \\
\hline Wasnik 2015 [72] & India & Rural & School-going & 435 & $33.6 \%$ & $9.2 \%$ & $57.2 \%$ & NR & NR \\
\hline Dhingra 2009 [29] & India & Rural & Unclear & 200 & NR & NR & $N R$ & NR & $0.0 \%{ }^{2}$ \\
\hline Khanna 2005 [1] & India & Urban & Mix & 330 & $4.8 \%$ & NR & $69.0 \%$ & $0.3 \%$ & NR \\
\hline Goel 2011 [9] & India & Urban & School-going & 478 & NR & NR & NR & NR & $92.9 \%$ \\
\hline Nair 2012 [73] & India & Urban & School-going & 3443 & $45.5 \%$ & $38.2 \%$ & $16.3 \%$ & NR & $97.6 \%$ \\
\hline Narayan 2001 [18] & India & Urban & School-going & 292 & $8.3 \%$ & $17.1 \%$ & $72.2 \%$ & NR & NR \\
\hline Omidvar 2010 [46] & India & Urban & School-going & 350 & $68.9 \%$ & NR & $19.1 \%$ & $11.1 \%$ & $81.7 \%^{\mathrm{b}}$ \\
\hline Thakre 2011 [12] & India & Urban & School-going & 241 & $60.6 \%$ & NR & $39.4 \%$ & NR & NR \\
\hline Yasmin 2013 [13] & India & Urban & School-going & 147 & $82.3 \%$ & $1.4 \%$ & $16.3 \%$ & $N R$ & $85.7 \%$ \\
\hline Bobhate 2011 [7] & India & Urban & Unclear & 241 & $43.2 \%$ & $N R$ & $41.5 \%$ & $15.4 \%$ & $N R$ \\
\hline Adhikari 2007 [5] & Nepal & Rural & School-going & 150 & $2.0 \%$ & $N R$ & $98.0 \%$ & NR & $4.0 \%$ \\
\hline Ali $2010[6]^{c}$ & Pakistan & Urban & Government school & 425 & $17.9 \%$ & $N R$ & $87.5 \%$ & $3.9 \%$ & $44.2 \%^{b}$ \\
\hline Ali $2010[6]^{c}$ & Pakistan & Urban & Out-of-school & 425 & $13.2 \%$ & NR & $81.0 \%$ & $6.6 \%$ & $45.9 \%^{b}$ \\
\hline Ali $2010[6]^{c}$ & Pakistan & Urban & Private school & 425 & $33.8 \%$ & $N R$ & $62.6 \%$ & $4.4 \%$ & $45.2 \%^{\mathrm{b}}$ \\
\hline \multicolumn{10}{|l|}{ West Asia } \\
\hline Poureslami 2002 [79] & Iran & Urban & School-going & 250 & NR & NR & NR & NR & $66.0 \%^{\mathrm{b}}$ \\
\hline
\end{tabular}


study in rural India reported poor fit and rashes than did girls using cloth [63], the cost of sanitary pads were a concern for some girls questioned in other studies in India [12, 15, 34], Tanzania [61], and Uganda [16]. Almost all of the 102 urban-living girls questioned in Kenya preferred sanitary pads for their convenience and reliability, but nearly half used cloth or a combination of cloth and sanitary pads to save money [50]. Tissue paper and cotton were also cited as absorbents for girls in various LMIC, with tissue paper reported by as many as $37.1 \%$ of ruralliving schoolgirls in Uganda [16].

A minority of girls in Egypt [30] and India [12, 46], no more than one in five, compared to $56.5 \%$ of girls in Nigeria [20] changed absorbents while at school. Most girls in Egypt [30] and Uganda [16] felt schools lacked privacy and most in India [12] and Nigeria [20] preferred to change materials at home. Insufficient latrines, water supplies and disposal infrastructure further presented a barrier for students in India [15, 67], Tanzania [61], and Uganda [16] to manage their periods at school.

Methods for disposing of materials beyond throwing them away with other trash included burning, burying, and flushing materials. Very few (2.5\%) girls in Egypt dispose of absorbents by burning them compared to $17.0-76.0 \%$ in India [12, 63, 73] and Nigeria [14, 40]. Indian girls in rural settings were significantly more likely to report burning materials than those in urban settings ( $p$-value $<0.05)$ [22]. Of those who reuse cloth, drying washed materials in sunlight rather than in hiding varied from 30.7\% of girls in urban Pakistan [6] to 44.3$72.4 \%$ of schoolgirls in India $[10,12,15,18,73]$. Schoolbased health education in India led to significant improvements in washing cloth with soap, in drying them in the sun and in disposing of them safely [17].

Reported bathing practices in India ranged from all 200 rural-living girls in one state abstaining during menstruation [29] to nearly all 3,443 girls in urban areas of another state bathing daily [73]. One study found that the practice of daily bathing was significantly higher among urban-living girls than rural-living girls $(p<0.05)$ [65], and another found that both a regular source of water and a private bathroom exclusive to a family had significant relationships with taking a daily bath $(p<0.001)$ [13]. In Turkey [27] and Nigeria [20], $11.9 \%$ and $72.5 \%$ of urbanliving girls reported increasing the number of baths they take. Girls in rural Kenya revealed that they wanted to bathe more frequently during their period, but were concerned about using limited water supplies and feared revealing to their family that they were menstruating [51]. A quasi-experimental study involving 698 girls in Iran showed that those who participated in 10 two-hour teacher-led sessions on pubertal changes engaged in regular bathing more than those who did not, and the difference was significant $(p$-value $<0.01)$ [79]. Another quasi-experimental study in Egypt found a significant increase in the number of girls bathing daily during their periods after participating in four $30-45 \mathrm{~min}$ health education sessions focused on menstruation ( $p$ value $<0.001$ ] [80]. Four studies in India defined satisfactory cleaning of genitalia to mean washing two or more times a day while menstruating; one-third to three-quarters of girls met this criterion [12, 13, 29, 34]. Unsatisfactory cleaning was significantly higher among rural-living girls than those in urban parts [22]. In a study evaluating the impact of school-based health education, the proportion of girls using soap to clean their genitalia significantly increased from 30.0 to $94.3 \%$ ( $p$-value $<0.01)$ [17].

Girls in Mexico who had previous knowledge of the physiology of menstruation were significantly more likely to know what was happening in their bodies and what to do, in terms of hygiene management, upon reaching menarche $(p$-value $<0.001)$ [24]. For schoolgirls in Jordan, being prepared prior to menarche resulted in more positive attitudes, and attitude had a significant positive correlation with practices ( $p$-value $<0.05)$ [36]. Schooling status among girls in Iran also had a significant positive correlation with practices $(p$-value $<0.01)[6,66]$.

\section{Conclusion}

An important limitation of this review is that vague measures are often used to describe the menstrual experiences of girls, which impede data aggregation and direct comparisons. For instance, studies used different yardsticks for adequate or inadequate knowledge, and used the terms premenstrual syndrome and dysmenorrhea loosely. Further, many studies had small sample sizes and relied heavily on self-report. Some studies had low response rates due to discomfort or limitations to discussing menstruation. Another limitation is that a majority of relevant data from included studies come from a limited number of countries and are not representative of all LMIC. Among the included countries and across all LMIC is great cultural variation, and the results presented here should be considered in light of these unique perspectives. Despite these limitations, the evidence presented allows for the following conclusions:

- Substantial numbers of girls in many countries have knowledge gaps and misconceptions about menstruation. This leaves them unprepared when they reach menarche and causes fear and anxiety.

- Mothers, other female relatives and female peers are their main sources of information and advice on menstruation. The information they receive, however, is not always timely nor adequate. Only some have access to additional information from sources such as mass media and the Internet. 
- Girls experience a variety of symptoms during menstruation-pain, headaches and fatigue. These symptoms combined with taboos result in their not being able to participate in household, school, or social activities.

- Very few girls seek health care when they experience menstrual health problems. If anything, they may resort to household remedies.

- Girls in poor urban and rural communities of LMIC are less likely to obtain and use sanitary pads. Instead, they use materials made at home with scraps of old cloth, cotton, paper, etc. Lack of privacy, access to clean water and functional toilets make it harder for them to manage their periods.

It is clear that far too many girls across LMIC are struggling with nearly complete ignorance of their normal biological maturation and its consequences, and when they do receive education, still struggle with inadequate sanitary materials and insufficient physical and emotional support. Although there is no convincing evidence that poor menstrual hygiene management leads to ascending reproductive tract infections [81] or causes lasting sequelae, this review underscores that coming to terms with menarche and navigating the shame and practical challenges associated with its management may cause girls great anxiety and sadness. There remains a need for further research into the physical, mental and social impacts of such distress. For example, being unprepared for menarche, being excluded and shamed during monthly periods, being hindered in self-care and uncared for when unwell, undermines a girl's sense of being in charge of her life, her sense of self-worth and her sense that the individuals and institutions around her are responsive to her needs. The huge and lasting impacts this can have on girls' lives remain to be studied.

In the short term, however, there are intervention studies that demonstrate the ability to improve girls' menstrual knowledge and hygiene management. Health education interventions like school-based sessions tested in India have resulted in improved understanding post-intervention [17], and similar programs in Egypt [80] and Iran [79] have improved the bathing practices of girls during their periods. Additionally, a quasi-experimental study in India that involved training of medical officers and providing reference tools led to statistically significant improvements in their case management of menstrual health problems for female patients between the ages of 15 and 24 [82].

Some exciting initiatives led by academics, international agencies and the private sector are also under way. Educating and encouraging parents to communicate with their daughters and sons about puberty and menstruation is being implemented by the Families Matter Program [83]. A five-year initiative by Columbia University has launched locally designed puberty booklets for girls and for boys in Tanzania, Ghana, Ethiopia, and Cambodia; these have been embraced by the Ministries of Education and of Health in all four countries [84]. Save the Children has also developed workbooks, modeled on those by Columbia University, for girls and boys in Nepal, Uganda and Malawi and is carrying out puberty education programs in multiple countries [85]. Similar efforts, such as CycleSmart $^{\mathrm{TM}}$ [86] and GrowUp Smart [87], are being implemented by Georgetown University's Institute of Reproductive Health in Rwanda and Guatemala. In 2014, UNESCO published a policy booklet with guidance to improve school administrators and teachers' abilities to educate and support girls and boys in classrooms [88]. Procter \& Gamble, a major producer of sanitary products, has launched communication programmes in several of the countries where it sells products with marketing approaches aimed at legitimizing family discussion of menstruation, and engaging and educating girls while building their self-esteem [89]. During its Celebrating Womanhood event in 2013, the Water Supply \& Sanitation Collaborative Council defined menstrual hygiene as a priority and outlined a 3-pronged approach that includes breaking the silence around this topic, ensuring hygienic management, and identifying mechanisms for safe reuse and disposal of materials [90]. Linking menstruation education with efforts to improve water, sanitation and disposal facilities in schools has also been actively promoted and implemented by UNICEF at the country and global levels [91].

While these initiatives are important and promising first steps, greater uptake and commitment is needed to fulfill the rights of girls related to menstrual knowledge, health and hygiene. Concerted multi-level efforts are required to achieve this. At the individual level, girls and boys need to be educated about puberty. At the family level, girls need support during their menstrual cycles. At the community level, we must improve access to sanitary products, running water, functional toilets and privacy. We need competent and caring health care workers who can respond to girls' questions and concerns, and to provide care when they have menstrual health problems. Finally, we need leaders who can change the perception of menarche and menstruation to one of normalcy and promise rather than of shame.

\section{Endnotes}

${ }^{1}$ Only descriptive studies with quantitative results are included in Tables 2, 3, 4, 5, 6 and 7.

\section{Abbreviations}

LMIC: Low- and middle-income countries; MHM: Menstrual hygiene management

\section{Acknowledgements}

Marni Sommer, Mailman School of Public Health, Colombia University reviewed and provided inputs on an earlier version of the paper. 
Asanthi Balapitiya, Ministry of Health, Sri Lanka, who interned with WHO in 2015, updated the search in July 2015 and completed initial data abstraction.

\section{Funding}

Sheila Patel was engaged by WHO to research and coauthor the paper. Venkatraman Chandra-Mouli is a staff member of the World Health. Organization. This is part of his work.

\section{Availability of data and materials}

Please contact corresponding author for data requests beyond what is available in tables and appendix.

\section{Authors' contributions}

This review was conceived by VCM. He supported SVP in carrying out the review and preparing the first draft of the paper. Initial findings were presented virtually by VCM and SVP at UNESCO's International Technical Consultation on Menstrual Hygiene Management and the Education Sector in July 2013. SVP updated the search, incorporated the new data and prepared a revised draft of the paper. VCM and SVP reviewed and approved the final draft.

\section{Authors' information}

No additional information

\section{Competing interests}

The authors declare that they have no competing interests.

\section{Ethics approval and consent to participate}

Not applicable as manuscript does not report on or involve use of any individual animal or human data or tissue.

\section{Author details}

${ }^{1}$ Department of Reproductive Health and Research, World Health Organization, Avenue Appia 20, 1211 Geneva 27, Switzerland. ²Department of Health Policy and Management, Gillings School of Global Public Health, University of North Carolina at Chapel Hill, 135 Dauer Drive, Chapel Hill, NC 27599, USA.

Received: 17 November 2016 Accepted: 21 February 2017 Published online: 01 March 2017

\section{References}

1. Khanna A, Goyal RS, Bhawsar R. Menstrual practices and reproductive problems: a study of adolescent girls in Rajasthan. J Health Manag. 2005;7(1):91-107.

2. Ersoy $B$, et al. Effects of different socioeconomic conditions on menarche in Turkish female students. Early Hum Dev. 2004;76(2):115-25.

3. Dongre AR, Deshmukh PR, Garg BS. The effect of community-based health education intervention on management of menstrual hygiene among rural Indian adolescent girls. World Health Popul. 2007;9(3):48-54.

4. Tang CS, Yeung DY, Lee AM. Psychosocial correlates of emotional responses to menarche among Chinese adolescent girls. J Adolesc Health. 2003;33(3):193-201

5. Adhikari $P$, et al. Knowledge and practice regarding menstrual hygiene in rural adolescent girls of Nepal. Kathmandu Univ Med J (KUMJ). 2007;5(3):382-6.

6. Ali TS, Rizvi SN. Menstrual knowledge and practices of female adolescents in urban Karachi, Pakistan. J Adolesc. 2010;33(4):531-41.

7. Bobhate P, Shrivastava S. A cross sectional study of knowledge and practices about reproductive health among female adolescents in an urban slum of Mumbai. J Fam Reprod Health. 2011;5(4):117-24.

8. Dasgupta A, Sarkar M. Menstrual hygiene: how hygienic is the adolescent girl? Indian J Community Med. 2008;33(2):77-80.

9. Goel MK, Kundan M. Psycho-social behaviour of urban Indian adolescent girls during menstruation. Australas Med J. 2011;4(1):49-52.

10. Shanbhag D, Shilpa R, D'Souza N, Josphine P, Singh J, Goud BR. Perceptions regarding menstruation and Practices during menstrual cycles among high school going adolescent girls in resource limited settings around Bangalore City, Karnataka, India. Int J Collab Res Inter Med Public Health. 2012:4(7):1353-62.

11. Tiwari H, Oza UN, Tiwari R. Knowledge, attitudes and beliefs about menarche of adolescent girls in Anand district, Gujarat. East Mediterr Health J. 2006;12(3-4):428-33.
12. Thakre SB, Thakre SS, Reddy M, Rathi N, Pathak K, Ughade S. Menstrual hygiene: knowledge and practice among adolescent school girls of Saoner, Nagpur district. J Clin Diagn Res. 2011;5(5):1027-33.

13. Yasmin S, Mallik S, Manna N, Ahmed A, Paria B. Menstrual hygiene among adolescent school students: an indepth cross-sectional study in an urban community of West Bengal, India. Sudan J Public Health. 2013;8(2):60-4.

14. Oche MO, Umar AS, Gana GJ, Ango JT. Menstrual health: the unmet needs of adolescent girls' in Sokoto, Nigeria. Sci Res Essays. 2012;7(3):410-8.

15. Ray S, Dasgupta A. Determinants of menstrual hygiene among adolescent girls: a multivariate analysis. Natl J Commun Med. 2012;3(2):294-301.

16. Boosey R, Prestwich G, Deave T. Menstrual hygiene management amongst schoolgirls in the Rukungiri district of Uganda and the impact on their education: a cross-sectional study. Pan Afr Med J. 2014;19:253.

17. Nemade D, Anjenaya S, Gujar R. Impact of health education on knowledge and practices about menstruation among adolescent school girls of Kalamboli, Navi-Mumbai. Health Popul Perspect Issues. 2009;32(4):167-75.

18. Narayan K, Srinivasa D, Pelto P, Veerammal S. Puberty rituals, reproductive knowledge and health of adolescent schoolgirls in South India. Asia-Pac Popul J. 2001;16(2):225-38.

19. Arora A, Mittal A, Panthania D, Mehta C, Bunger R. Impact of health education on knowledge and practices about menstruation among adolescent school girls of rural part of district Ambala, Haryana. Ind J Comm Health. 2013;25(4):492-7.

20. Lawan UM, Yusuf NW, Musa AB. Menstruation and menstrual hygiene amongst adolescent school girls in Kano, Northwestern Nigeria. Afr J Reprod Health. 2010;14(3):201-7.

21. Zegeye DT, Megabiaw B, Mulu A. Age at menarche and the menstrual pattern of secondary school adolescents in northwest Ethiopia. BMC Womens Health. 2009;9:29.

22. Thakre SB, et al. Urban-rural differences in menstrual problems and practices of girl students in Nagpur, India. Indian Pediatr. 2012;49(9):733-6.

23. Udgiri R, Angadi MM, Patil S, Sorganvi V. Knowledge and practices regarding menstruation among adolescent girls in an urban slum, Bijapur. J Indian Med Assoc. 2010;108(8):514-6.

24. Marvan ML, Molina-Abolnik M. Mexican adolescents' experience of menarche and attitudes toward menstruation: role of communication between mothers and daughters. J Pediatr Adolesc Gynecol. 2012;25(6):358-63.

25. Sharma M, Gupta S. Menstrual pattern and abnormalities in the high school girls of Dharan: a cross sectional study in two boarding schools. Nepal Med Coll J. 2003;5(1):34-6.

26. Adinma ED, Adinma Jl. Menstrual characteristics amongst south-eastern Nigerian adolescent school girls. West Afr J Med. 2009;28(2):110-3.

27. Reis N, Kilic D, Engin R, Karabulutlu O. Sexual and reproductive health needs of adolescent girls from conservative and low-income families in Erzurum, Turkey. Health Popul Perspect Issues. 2011;3(6):370-7.

28. Bosch AM, Hutter I, van Ginneken JK. Perceptions of adolescents and their mothers on reproductive and sexual development in Matlab, Bangladesh. Int J Adolesc Med Health. 2008;20(3):329-42.

29. Dhingra R, Kumar A, Kour M. Knowledge and practices related to menstruation among tribal (Gujjar) adolescent girls. Ethno-Medicine. 2009;3(1):43-8.

30. El-Gilany AH, Badawi K, El-Fedawy S. Menstrual hygiene among adolescent schoolgirls in Mansoura, Egypt. Reprod Health Matters. 2005;13(26):147-52.

31. Gumanga SK, Kwame-Aryee RA. Menstrual characteristics in some adolescent girls in Accra, Ghana. Ghana Med J. 2012;46(1):3-7.

32. Dambhare DG, Wagh SV, Dudhe JY. Age at menarche and menstrual cycle pattern among school adolescent girls in Central India. Glob J Health Sci. 2012;4(1):105-11.

33. Kotecha PV, et al. Reproductive health awareness among rural school going adolescents of Vadodara district. Indian J Sex Transm Dis. 2009;30(2):94-9.

34. Mudey A, Kesharwani N, Mudey GA, Goyal RC. A cross-sectional study on awareness regarding safe and hygienic practices amongst school going adolescent girls in rural area of Wardha District, India. Glob J Health Sci. 2010;2(2):225-31.

35. Ray $\mathrm{S}$, et al. Knowledge and information on psychological, physiological and gynaecological problems among adolescent schoolgirls of eastern India. Ethiop J Health Sci. 2011;21(3):183-9.

36. Jarrah SS, Kamel AA. Attitudes and practices of school-aged girls towards menstruation. Int J Nurs Pract. 2012;18(3):308-15.

37. Lee LK, et al. Menstruation among adolescent girls in Malaysia: a crosssectional school survey. Singapore Med J. 2006;47(10):869-74. 
38. Wong LP. Attitudes toward menstruation, menstrual-related symptoms, and premenstrual syndrome among adolescent girls: a rural school-based survey. Women Health. 2011:51(4):340-64.

39. Wong LP. Premenstrual syndrome and dysmenorrhea: urban-rural and multiethnic differences in perception, impacts, and treatment seeking. J Pediatr Adolesc Gynecol. 2011;24(5):272-7.

40. Aniebue UU, Aniebue PN, Nwankwo TO. The impact of pre-menarcheal training on menstrual practices and hygiene of Nigerian school girls. Pan Afr Med J. 2009;2:9.

41. Hiyasu $Z$, et al. Sexual and reproductive health communication between mothers and their adolescent daughters in northern Nigeria. Health Care Women Int. 2012;33(2):138-52.

42. Ajah LO, et al. Adolescent reproductive health challenges among schoolgirls in southeast Nigeria: role of knowledge of menstrual pattern and contraceptive adherence. Patient Prefer Adherence. 2015;9:1219-24.

43. Chandraratne NK, Gunawardena NS. Premenstrual syndrome: the experience from a sample of Sri Lankan adolescents. J Pediatr Adolesc Gynecol. 2011;24(5):304-10

44. Abd El-Hameed NA, Mohamed MS, Ahmed NH, Ahmed ER. Assessment of dysmenorrhea and menstrual hygiene practices among adolescent girls in some nursing schools at IL-Minia governorate, Egypt. J Am Sci. 2011;7(9):216-23.

45. Eswi $A$, Helal $H$, Elarousy W. Menstrual attitude and knowledge among Egyptian female adolescents. J Am Sci. 2012;8(6):555-65.

46. Omidvar S, Begum K. Factors influencing hygienic practices during menses among girls from south India: a cross sectional study. Int J Collab Res Intern Med Public Health. 2010;2(12):411-23.

47. Wong LP. Attitudes towards dysmenorrhoea, impact and treatment seeking among adolescent girls: a rural school-based survey. Aust J Rural Health. 2011;19(4):218-23.

48. Wong LP, Khoo EM. Menstrual-related attitudes and symptoms among multi-racial Asian adolescent females. Int J Behav Med. 2011;18(3):246-53.

49. Sommer M. Ideologies of sexuality, menstruation and risk: girls' experiences of puberty and schooling in northern Tanzania. Cult Health Sex. 2009;11(4):383-98.

50. Crichton J, et al. Emotional and psychosocial aspects of menstrual poverty in resource-poor settings: a qualitative study of the experiences of adolescent girls in an informal settlement in Nairobi. Health Care Women Int. 2013;34(10):891-916.

51. Mason L, et al. 'We keep it secret so no one should know'-a qualitative study to explore young schoolgirls attitudes and experiences with menstruation in rural western Kenya. PLoS One. 2013;8(11):e79132.

52. Munthali AC, Zulu EM. The timing and role of initiation rites in preparing young people for adolescence and responsible sexual and reproductive behaviour in Malawi. Afr J Reprod Health. 2007;11(3):150-67.

53. McMahon SA, et al. 'The girl with her period is the one to hang her head' Reflections on menstrual management among schoolgirls in rural Kenya. BMC Int Health Hum Rights. 2011;11:7.

54. Sommer M. An early window of opportunity for promoting girls' health: Policy implications of the girl's puberty book project in tanzania. Int Electron J Health Educ. 2011;14:77-92.

55. Dorgbetor G. Mainstreaming MHM in schools through the play-based approach: lessons learned from Ghana. Waterlines. 2015;34(1):41-50.

56. Marvan ML, Vacio A, Espinosa-Hernandez G. Menstrual-related changes expected by premenarcheal girls living in rural and urban areas of Mexico. Soc Sci Med. 2003;56(4):863-8.

57. Marvan ML, Vacio A, Espinosa-Hernandez G. A comparison of menstrual changes expected by pre-menarcheal adolescents and changes actually experienced by post-menarcheal adolescents in Mexico. J Sch Health. 2001;71(9):458-61.

58. Pitangui $A C$, et al. Menstruation disturbances: prevalence, characteristics, and effects on the activities of daily living among adolescent girls from Brazil. J Pediatr Adolesc Gynecol. 2013;26(3):148-52.

59. Santina T, Wehbe N, Ziade F. Exploring dysmenorrhoea and menstrual experiences among Lebanese female adolescents. East Mediterr Health J. 2012;18(8):857-63

60. Chaudhuri A, Singh A. How do school girls deal with dysmenorrhoea? J Indian Med Assoc. 2012;110(5):287-91.

61. Sommer M. Where the education system and women's bodies collide: The social and health impact of girls' experiences of menstruation and schooling in Tanzania. J Adolesc. 2010;33(4):521-9.

62. Patil MS, Angadi MM. Menstrual pattern among adolescent girls in rural area of Bijapur. Al Ameen J Med Sci. 2013;6(1):17-20.
63. Rana B, Prajapati A, Sonaliya KN, Shah V, Patel M, Solanki A. An assessment of menstrual hygiene practices amongst adolescent females at Kheda district of Gujarat state, India. Healthline J. 2015;6(1):23-9.

64. Sharma $P$, et al. Problems related to menstruation amongst adolescent girls. Indian J Pediatr. 2008;75(2):125-9.

65. Juyal R, Kandpal SD, Semwal J. Social aspects of menstruation related practices in adolescent girls of district Dehradun. Indian J Community Health. 2013;25(3):213-6.

66. Haque SE, et al. The effect of a school-based educational intervention on menstrual health: an intervention study among adolescent girls in Bangladesh. BMJ Open. 2014;4(7):e004607.

67. Bodat S, Ghate MM, Majumdar JR. School absenteeism during menstruation among rural adolescent girls in Pune. Natl J Community Med. 2013;4(2):212-6.

68. Joshi D, Buit G, González-Botero D. Menstrual hygiene management: education and empowerment for girls? Waterlines. 2015;34(1):51-67.

69. Montgomery $P$, et al. Sanitary pad interventions for girls' education in Ghana: a pilot study. PLoS One. 2012;7(10):e48274.

70. Oster E, Thornton R. Menstruation, sanitary products, and school attendance: evidence froma randomized evaluation. Am Econ J. 2011;3(1):91-100.

71. Mason L, Laserson K, Oruko K, et al. Adolescent schoolgirls' experiences of menstrual cups and pads in rural western Kenya: a qualitative study. Waterlines. 2015;34(1):15-30.

72. Kabir $\mathrm{H}$, et al. Treatment-seeking for selected reproductive health problems: behaviours of unmarried female adolescents in two low-performing areas of Bangladesh. Reprod Health. 2014;11:54.

73. Nair MK, et al. Menstrual disorders and menstrual hygiene practices in higher secondary school girls. Indian J Pediatr. 2012;79 Suppl 1:S74-8.

74. Baidya S, Debnath M, Das R. A study of reproductive health problems among rural adolescent girls of Mohanpur block of West Tripura district. Al Ameen J Med Sci. 2014;7(1):78-82.

75. Wong LP, Khoo EM. Dysmenorrhea in a multiethnic population of adolescent Asian girls. Int J Gynaecol Obstet. 2010;108(2):139-42.

76. Poureslami M. Assessing knowledge, attitudes, and behavior of adolescent girls in suburban districts of Tehran about dysmenorrhea and menstrual hygiene. J Int Womens Stud. 2002;3(2):51-61.

77. Eryilmaz G, Ozdemir F. Evaluation of menstrual pain management approaches by Northeastern Anatolian adolescents. Pain Manag Nurs. 2009;10(1):40-7.

78. Wasnik VR, Dhumale D, Jawarkar AK. A study of the menstrual pattern and problems among rural school going adolescent girls of Amravati district of Maharashtra, India. Int J Res Med Sci. 2015;33(55):1252-6.

79. Fakhri $\mathrm{M}$, et al. Promoting menstrual health among persian adolescent girls from low socioeconomic backgrounds: a quasi-experimental study. BMC Public Health. 2012;12:193.

80. Allah ESA, Elsabagh EEM. Impact of health education intervention on knowledge and practice about menstruation among female secondary school students in Zagazig City. J Am Sci. 2011;7(9):737-47.

81. Sumpter C, Torondel B. A systematic review of the health and social effects of menstrual hygiene management. PLoS One. 2013;8(4):e62004.

82. Nanda PMA, Mukherjee S, Barua A, Mehl GL, Venkatraman CM. A study to evaluate the effectiveness of WHO tools: orientation programme on adolescent health for health care providers and adolescent job aid in India. Geneva: International Center for Research on Women; 2012.

83. Vandenhoudt $\mathrm{H}$, et al. Evaluation of a U.S. evidence-based parenting intervention in rural Western Kenya: from parents matter! To families matter! AIDS Educ Prev. 2010;22(4):328-43.

84. Sommer M, Ackatia-Armah N, Connolly S, Smiles D. A comparison of the menstruation and education experiences of girls in Tanzania, Ghana, Cambodia and Ethiopia. Compare. 2014;45(4):589-609.

85. Children, S.t. Adolescent Sexual and Reproductive Health. 2015. Available from: http://www.savethechildren.org/site/c.8rKLIXMGIpl4E/b.9080949/k. F576/Adolescent_Sexual_and_Reproductive_Health.htm.

86. Health, I.f.R. Meeting the needs of adolescents: Introducing CycleSmart ${ }^{\mathrm{TM}}$. 2013. Available from: http://irh.org/blog/meeting-the-needs-of-adolescentsintroducing-the-cyclesmart-kit/.

87. Health, I.f.R. A3 project. Available from: http://irh.org/projects/a3_project/. Accessed 15 oct 2014

88. Kettaneh APS, Todesco M. Good policy and practice booklet no. 9: puberty education and menstrual hygiene management. Paris: United Nations Educational, Scientific and Cultural Organization; 2014.

89. Always. Tips \& advice: "the talk". Available from: http://always.com/en-us/ tips-and-advice/the-talk. Accessed 15 oct 2014. 
90. George R. Celebrating womanhood: how better menstrual hygiene management is the path to better health, dignity and business. Geneva: Water Supply \& Sanitation Collaboration Council; 2013.

91. Sommer M. V. E., Worthington, N., Sahin M. WASH in schools empowers girls' education: proceedings of the menstrual hygiene management in schools virtual conference 2012. in Menstrual Hygiene Management in Schools Virtual Conference. New York, NY: United Nations Children's Fund and Columbia University; 2012.

92. Kanotra SK, Bangal VB, Bhavthankar DP. Menstrual pattern and problems among rural adolescent girls. International Journal of Biomedical and Advance Research. 2013; 4(8):551-4.

Submit your next manuscript to BioMed Central and we will help you at every step:

- We accept pre-submission inquiries

- Our selector tool helps you to find the most relevant journal

- We provide round the clock customer support

- Convenient online submission

- Thorough peer review

- Inclusion in PubMed and all major indexing services

- Maximum visibility for your research

Submit your manuscript at www.biomedcentral.com/submit
Biomed Central 